\title{
Using nutrient foramina to differentiate human from non-human long bone fragments in bioarchaeology and forensic anthropology
}

\author{
Brigida Corrieri ${ }^{a}$ and Nicholas Márquez-Grant ${ }^{a *}$ \\ Cranfield Forensic Institute, Cranfield University, Defence Academy of the United Kingdom, \\ Shrivenham SN6 8LA, United Kingdom
}

Abbreviated title: Human/nonhuman bone differentiation using nutrient foramina

Corresponding author: Nicholas Márquez-Grant, PhD, n.marquezgrant@ cranfield.ac.uk, tel. +44 (0) 1793314466

\begin{abstract}
Long bone shaft fragments can be found isolated in archaeological and forensic contexts, such as in mass fatality incidents. When diagnostic morphological landmarks are not visible, the assessment of a human or non-human origin of a bone fragment can be challenging. Further methods need to be developed. In long bones, the presence of a nutrient foramen on fragments that do not show any diagnostic landmarks can make the assessment of the origin of the bone still possible.

In this paper, human long bones were compared to those of the following species: chicken (Gallus gallus domesticus), duck (Cairina moschata), sheep (Ovis aries), pig (Sus scrofa domesticus), and deer (fallow deer, Dama dama, and roe deer, Capreolus capreolus).

Macroscopic evaluation of location, direction and appearance, and micro-CT scanning in order to measure angle and shape of canal entrance, were applied in this study to differentiate human from non-human nutrient foramina on long bone shafts.

Observations regarding the location and direction of nutrient foramina were proven to be different between human and non-human bones; however, these two features might not be exploitable in cases of highly fragmented bones. The foramina appearance was the most reliable for the origin identification, although the shape of the canal entrance and its angle at the cortical bone, obtained
\end{abstract}


from micro-CT scans, were also useful parameters. For a correct identification of a fragment, one parameter may not be enough and it is advisable to employ as many features as possible.

This research demonstrates that nutrient foramina have potential as a reliable bone feature for the distinction between human and non-human fragmented and incomplete long bones.

Keywords: Bone fragmentation; Human/non-human differentiation; Non-destructive methods; Micro Computed Tomography; forensic anthropology

\section{INTRODUCTION}

Nutrient foramina are openings through which the blood vessels enter bones. On long bones, nutrient arteries and peripheral nerves reach the marrow cavity from the outer surface through the nutrient foramina, which in most cases can be distinguished from any other cavity by the presence of a vascular groove (Beisaw, 2013). The blood carried by the nutrient arteries into the bone is essential for the growth, nutrition, and repair of the bones (Marenzana and Arnett, 2013). Indeed, a nutrient foramen is the site of the original centre of ossification of a long bone, as the vessels passing through it are derived from those that supplied blood to the initial ossifying cartilage (Rao and Kothapalli, 2014). For this reason, the growing end of a long bone is indicated by the direction of the main nutrient foramen.

The blood vessels entering through the foramina are also vital for bone metabolism, the lifelong remodelling process where new bone tissue is produced in response to the wear and tear caused by mechanical loading and locomotion (Klein-Nulend and Bacabac, 2012). Therefore, the extent of blood flow and hence the individual (human or non-human) activity level can be inferred from the cross-sectional area of the nutrient canal (Seymour et al., 2012; Ward et al., 2000).

The studies that have focused on nutrient foramina (site, size, and direction) are mainly of clinical and surgical interest, as a thorough knowledge of the characteristics of the nutrient canal and the blood flow that passes through it is vital, for example, in orthopaedic surgery (Gainor and Metzler, 1986), fracture diagnosis and union, tumour resection, and reconstructive surgery of skeletal abnormalities (Xue et al., 2016). 
Very few studies have examined non-human nutrient foramina (Dongchoon, 2013; Hughes, 1952; Sim and Dongchoon, 2014; Witkowska et al., 2014). Those undertaken investigate the number, site, position and direction of the nutrient foramina of some common non-human species, such as dogs (Dongchoon, 2013; Sim and Dongchoon, 2014) and guinea pigs (Witkowska et al., 2014), and fall within the field of veterinary medicine.

Even fewer studies have focused on the comparison between human and non-human nutrient foramina, in the field of comparative anatomy or forensic anthropology. Johnson et al. (2017) measured the location (based on the calculation of the foraminal index, not used in this study), direction, length, angle, circumference and area of the main nutrient canal in human, pig and sheep humeri and femora, in order to identify new parameters that could be used in the differentiation between human and non-human bones in forensic contexts. In this latter study, the circumference and cross-sectional area of the nutrient canal were not found to be useful for human/non-human differentiation, as there were no significant differences among the species considered. However, the canal length was found to be a discriminating parameter. A limitation of this study, however, is that only 36 bones were analysed, and only two non-human species were considered. Furthermore, since Johnson et al.'s (2017) study focused only on humeri and femora, its results might not be applicable in cases where other long bones such as radii, ulnae or tibiae are found.

When fragmented bones are found in both forensic (e.g. mass fatality incidents, crime scenes) and archaeological contexts, one of the first questions to address is whether or not the remains are human (Anstett and Dreyfus, 2015). Some contexts may include both human and non-human bone and this question is particularly important in commingled cases. Incomplete long bone shafts can be particularly challenging to identify, as there are similarities between human and some non-human species; if none of the diagnostic landmarks can be observable, the human/nonhuman origin identification of the fragments is considered possible only with microscopic and biomolecular methods (Dirkmaat, 2014), which can be time consuming and costly.

One of the macroscopic features considered as useful for the differentiation between human and non-human bone is cortical thickness (France, 2009). Non-human mammal bones tend to be denser and thicker relative to size than human ones. In humeri and femora the cortical thickness is about $1 / 4$ of the total bone diameter in humans, and $1 / 2$ in non-humans; however, this is a very generic rule, as in many cases the cortical thickness may be greater in humans than in other mammals. For example, the cortical bone at the femoral mid-shaft in humans was proved by Croker et al. (2009) to be thicker than in other mammals, such as sheep and kangaroo: the cortical thickness index, or proportion of shaft diameter occupied by the cortex, is $51.5 \%$ in humans, $34.6 \%$ in kangaroos, and 
$25 \%$ in sheep. This may be due to the greater load on the human femur, as in humans a larger body mass is carried on two legs, instead of four (Croker et al. 2009). Rerolle et al. (2013) used CT to determine if the corticomedullary index (CMI), defined by the ratio of the diameter of the medullary cavity to the total diameter of bone could be used to distinguish between human and non-human long bones. Measurements were taken from CT scans of human, pig, dog, and sheep femora, tibiae and fibulae. However, the origin identification based on the CMI proved accurate for only $22.6 \%$ of the samples used. It was concluded that the calculation of the CMI was not an effective method for determining the human or non-human origin of bone remains. It is also necessary to consider that bone thickness can vary according to bone section and side. Furthermore, physical activity makes the cortical thickness too variable to be used as a parameter to distinguish human from non-human bones, especially in a context with bone fragmentation (Warden et al., 2014).

The aim of this study was to assess whether further differences between nutrient foramina in human and non-human long bones could be found. Location and direction have been explored as identification parameters in other studies (Dongchoon, 2013; Hughes, 1952; Johnson et al., 2017); but the present study is the first in the field where the appearance of the nutrient foramina is considered as a potential parameter for the identification of bone fragments. Moreover, this paper aimed to evaluate whether these potential differences could be observed by a macroscopic and noninvasive method. This study has applications for both forensic and archaeological cases.

\section{MATERIALS AND METHODS}

The non-human species included in the study - chicken, duck, sheep, pig, and deer - were chosen because their long bones shafts share similar characteristics with human long bones, making their identification potentially challenging if they are found in a fragmentary state. Furthermore, in the United Kingdom where this study took place, the remains of these species can be commonly found in archaeological and forensic contexts. A survey of what species to select was undertaken in a previous study (Corrieri, 2018). The fragmented bones of chicken and duck can be misidentified as human juvenile bones, especially the long bones (Evans, 2016). The justification for using specific mammal species is that the fragmented limb bones of pig, sheep and deer may be misidentified as adult human bones. Dog long bones were assessed in a previous study (Corrieri, 2018) and it was deemed that due to the number of dog breeds a separate study would be advisable. Cow and horse were excluded because their limb bones are much more robust than the human ones and have a thick, wood-grain like cortex (Dumont, 2010). Thus, in total, the study sample comprised a total of 364 human and non-human limb bones: left and right humeri, radii, ulnae, femora and tibiae, or 
tibiotarsi for birds (Table 1). Fibulae were not included, as the non-human species considered in this study have an extremely gracile fibula (chicken and duck) or have a bony prominence on the proximal lateral tibia, with no shaft (sheep and deer) (see Corrieri, 2018). Among the species considered, only the pig has a fibula, but this bone is very different in size and morphology from the human fibula; human and pig fibula share a medial location of the nutrient foramen, but even in a fragmentary state they cannot be misidentified, because of their peculiar shapes.

Table 1. Number of bones considered for this study, separated per species and long bone. In brackets the number of bones scanned is shown, where $\mathrm{L}=\mathrm{left}$ and $\mathrm{R}=$ right. An additional deer radius and ulna were scanned to counterproof the results of the first two scans, as the foramina on these bones were extremely small and difficult to see. Only one pig radius and ulna were available for scanning. An additional human left tibia was scanned; the first left tibia scanned showed tibial periostitis, but it was decided to scan also one that was unaffected by a pathology, for more consistent results. Total limb bones used: 364

\begin{tabular}{|c|c|c|c|c|c|c|}
\hline & $\begin{array}{c}\text { Human } \\
\text { Homo } \\
\text { sapiens }\end{array}$ & $\begin{array}{c}\text { Sheep } \\
\text { Ovis aries }\end{array}$ & $\begin{array}{c}\text { Deer } \\
\text { Dama d. } \\
\text { Capreolus } c .\end{array}$ & $\begin{array}{c}\text { Pig } \\
\text { Sus scrofa } \\
\text { domesticus }\end{array}$ & $\begin{array}{c}\text { Chicken } \\
\text { Gallus } \\
\text { gallus }\end{array}$ & $\begin{array}{c}\text { Duck } \\
\text { Cairina } \\
\text { moschata }\end{array}$ \\
\hline Humerus & $\begin{array}{r}22 \\
(2,1 \mathrm{~L}, 1 \mathrm{R})\end{array}$ & $\begin{array}{r}11 \\
(2,1 \mathrm{~L}, 1 \mathrm{R})\end{array}$ & $\begin{array}{r}10 \\
(2,1 \mathrm{~L}, 1 \mathrm{R})\end{array}$ & $\begin{array}{r}10 \\
(2,1 \mathrm{~L}, 1 \mathrm{R})\end{array}$ & $\begin{array}{r}10 \\
(2,1 \mathrm{~L}, 1 \mathrm{R})\end{array}$ & $\begin{array}{r}4 \\
(2,1 \mathrm{~L}, 1 \mathrm{R})\end{array}$ \\
\hline Radius & $\begin{array}{r}26 \\
(2,1 \mathrm{~L}, 1 \mathrm{R})\end{array}$ & $\begin{array}{r}10 \\
(2,1 \mathrm{~L}, 1 \mathrm{R})\end{array}$ & $\begin{array}{r}10 \\
(3,1 \mathrm{~L}, 2 \mathrm{R})\end{array}$ & $\begin{array}{r}9 \\
(1 \mathrm{~L})\end{array}$ & $\begin{array}{r}10 \\
(2,1 \mathrm{~L}, 1 \mathrm{R})\end{array}$ & $\begin{array}{r}4 \\
(2,1 \mathrm{~L}, 1 \mathrm{R})\end{array}$ \\
\hline Ulna & $\begin{array}{r}23 \\
(2,1 \mathrm{~L}, 1 \mathrm{R})\end{array}$ & $\begin{array}{r}9 \\
(2,1 \mathrm{~L}, 1 \mathrm{R})\end{array}$ & $\begin{array}{r}9 \\
(3,1 \mathrm{~L}, 2 \mathrm{R})\end{array}$ & $\begin{array}{r}9 \\
(1 \mathrm{~L})\end{array}$ & $\begin{array}{r}10 \\
(2,1 \mathrm{~L}, 1 \mathrm{R})\end{array}$ & $\begin{array}{r}4 \\
(2,1 \mathrm{~L}, 1 \mathrm{R})\end{array}$ \\
\hline Femur & $\begin{array}{r}26 \\
(2,1 \mathrm{~L}, 1 \mathrm{R})\end{array}$ & $\begin{array}{r}8 \\
(2,1 \mathrm{~L}, 1 \mathrm{R})\end{array}$ & $\begin{array}{r}9 \\
(2,1 \mathrm{~L}, 1 \mathrm{R})\end{array}$ & $\begin{array}{r}14 \\
(2,1 \mathrm{~L}, 1 \mathrm{R})\end{array}$ & $\begin{array}{r}10 \\
(2,1 \mathrm{~L}, 1 \mathrm{R})\end{array}$ & $\begin{array}{r}4 \\
(2,1 \mathrm{~L}, 1 \mathrm{R})\end{array}$ \\
\hline $\begin{array}{c}\text { Tibia/ } \\
\text { Tibiotarsus }\end{array}$ & $\begin{array}{r}33 \\
(3,2 \mathrm{~L}, 1 \mathrm{R})\end{array}$ & $\begin{array}{r}27 \\
(2,1 \mathrm{~L}, 1 \mathrm{R})\end{array}$ & $\begin{array}{r}9 \\
(2,1 \mathrm{~L}, 1 \mathrm{R})\end{array}$ & $\begin{array}{r}10 \\
(2,1 \mathrm{~L}, 1 \mathrm{R})\end{array}$ & $\begin{array}{r}10 \\
(2,1 \mathrm{~L}, 1 \mathrm{R})\end{array}$ & $\begin{array}{r}4 \\
(2,1 \mathrm{~L}, 1 \mathrm{R})\end{array}$ \\
\hline Total & 130 & 65 & 47 & 52 & 50 & 20 \\
\hline
\end{tabular}

The human individuals considered for the study were both juvenile and adult, of unknown sexes, and of modern date $\left(19^{\text {th }}\right.$ - early $20^{\text {th }}$ century and contemporary for some non-human species); most of them had no apparent pathological condition affecting the shaft, although some of the samples showed osteoarthritis at the epiphyses. The human bones and part of the non-human ones employed 
for this research derived from the reference collection of Cranfield Forensic Institute, UK. Most of the non-human bones were obtained from butchers, from the reference collection at Oxford Archaeology (South OA, Oxford, UK) and from the collection of the Grant Museum of Zoology in London, UK.

All 364 bones were macroscopically analysed to identify the location, appearance and direction of the primary nutrient foramen, where the main artery runs, as each long bone might have subsidiary, smaller nutrient foramina (Bostrom et al., 2000).

As for the location, the section of the shaft where the foramen is located was considered (e.g. proximal, medial, etc.), and when possible, the presence of close features such as muscle markings was taken into account and recorded. The foraminal index (Hughes, 1952), which is usually used to give a percentage value to the nutrient foramen location (in terms of distance from the epiphyses) was not used in this study, because it would be of no use in contexts where bones are incomplete and fragmented.

To define the appearance of the foramina, features such as shape, vascular groove characteristics and orientation were observed, using a magnifying lens. The direction of the foramina was established with a $27 \mathrm{G} \times(0.4 \times 19 \mathrm{~mm})$ hypodermic needle (Campos et al., 1987; Johnson et al., 2017).

\section{Micro CT scanning}

Micro Computed Tomography (micro-CT) was employed in this study because it is a high resolution imaging method that allows to carry out non-destructive analysis of very small features such as nutrient foramina. Micro-CT is a high-resolution X-ray based imaging modality that enables the acquisition of digital images and the processing of 3D images of small samples (Gantt et al., 2007, Sisniega et al., 2014). Micro-CT is used in a variety of fields, such as dental research, anatomical imaging, material analysis, pharmaceutical research, comparative anatomy (mainly humans-primates) and in vivo animal and plant testing (Stock, 2011). It is used in palaeoanthropology and biological/forensic anthropology, particularly for age and cortical thickness estimation, pathology diagnosis and individual identification (Wu and Schepartz, 2009; Franklin et al., 2016).

Out of the 364 bones, 61 were selected for micro CT-scanning, ensuring that all the species considered in this study and both adult and juvenile individuals were included (Corrieri, 2018, 
Table 5.8). The bones were scanned with a Nikon Metris X-tek XT H 225 micro-CT scanner. The largest bones were cut with a band saw, in order to sample the area that had the primary nutrient foramen. The bones were vertically scanned in bundles, with individual bones wrapped in plastic bags to allow for digital separation of the data for each bone. The settings, which were kept constant for all the samples, were as follows: $500 \mathrm{~ms}$ exposure time, $100 \mathrm{kV}, 50 \mu \mathrm{A}$, system set to optimize projections (usually 1571), with two frames per projection. The data collected had a voxel size of $0.137 \mathrm{~mm}$.

The micro-CT images were then processed with CT Pro software and manipulated with VG Studio Max software (v. 2.1), in order to detect the shape of the nutrient canal entrance and calculate the angle at which the canal enters the bone. To isolate the section of the bone showing the nutrient foramen, the region of interest was extracted; the object was oriented using simple registration, to specify the coordinate system. Surface determination and extraction were carried out in order to detect the shape of the canal entrance on the YZ plane (proximal-distal/distal proximal view, depending on the direction) and on the XY plane (exterior-interior view), and to calculate the angle on the $\mathrm{XZ}$ plane (side view). The angle at which the nutrient canal enters the long bone shaft was measured using the three points angle tool of the VG Studio MAX software. Since the same results were obtained using the same settings, a set number of three repeats for each bone was considered satisfactory.

\section{RESULTS}

The results are presented below according to the analysis undertaken on primary nutrient foramina of human and non-human limb bones, analysed using morphological examination (for location, appearance and direction) and micro-CT (for foramina shapes and nutrient canal angle).

\section{Location}

The nutrient foramina locations, according to species and bones, are summarized in Table 2 (below).

Table 2. Nutrient foramina locations ${ }^{1}$ 


\begin{tabular}{|c|c|c|c|c|c|c|}
\hline & Human & Sheep & Deer & Pig & Chicken & Duck \\
\hline Humerus & $\mathrm{A}, \mathrm{D}, \mathrm{ML}$ & $\mathrm{PO}, \mathrm{D}, \mathrm{LL}$ & $\mathrm{PO}, \mathrm{D}, \mathrm{LL}$ & $\begin{array}{c}\mathrm{PO}, \mathrm{D}, \mathrm{LL} \\
\text { or } \mathrm{ML}\end{array}$ & $\mathrm{L}, \mathrm{PR}$ & $\mathrm{L}, \mathrm{MS}$ \\
\hline Radius & $\mathrm{PO}, \mathrm{PR}, \mathrm{ML}$ & $\begin{array}{l}\text { PO, PR, on } \\
\text { attach. with } \\
\text { ulna }\end{array}$ & PO, PR, LL & $\mathrm{PO}, \mathrm{PR}$ & $\begin{array}{c}\text { PO or } \mathrm{M}, \\
\text { MS }\end{array}$ & $\mathrm{PO}, \mathrm{MS}$ \\
\hline Ulna & $\mathrm{M}, \mathrm{PR}$ & M, PR & M, D & $\mathrm{M}, \mathrm{PR}$ & $\mathrm{M}, \mathrm{PR}$ & $\mathrm{M}, \mathrm{PR}$ \\
\hline Femur & $\begin{array}{l}\text { PO, PR, on } \\
\text { linea aspera } \\
\text { (or } \\
\text { medial/lateral } \\
\text { to it) }\end{array}$ & $\mathrm{A}, \mathrm{PR}$ & $\mathrm{A}, \mathrm{PR}$ & $\begin{array}{c}\text { PO, D or } \\
\text { MS }\end{array}$ & $\begin{array}{c}\mathrm{PO}, \mathrm{MS}, \text { on } \\
\text { or lat to } \\
\text { muscle } \\
\text { marking }\end{array}$ & $\begin{array}{c}\text { PO, MS, on } \\
\text { or lat to } \\
\text { muscle } \\
\text { marking }\end{array}$ \\
\hline $\begin{array}{c}\text { Tibia/ } \\
\text { Tibiotarsus }\end{array}$ & $\begin{array}{c}\text { PO, PR } \\
\text { (can be LL) }\end{array}$ & $\mathrm{L}, \mathrm{PR}, \mathrm{PL}$ & $\mathrm{L}, \mathrm{PR}, \mathrm{PL}$ & $\mathrm{L}, \mathrm{PR}, \mathrm{PL}$ & $\mathrm{A}, \mathrm{PR}, \mathrm{ML}$ & $\mathrm{A}, \mathrm{PR}, \mathrm{ML}$ \\
\hline
\end{tabular}

${ }^{1} \mathrm{~A}=$ Anterior; $\mathrm{PO}=$ Posterior; $\mathrm{PR}=$ Proximal; $\mathrm{D}=$ Distal; $\mathrm{M}=$ Medial; $\mathrm{L}=$ Lateral; $\mathrm{MS}=$ Middle-shaft; $\mathrm{ML}=$ Medially Located; LL= Laterally Located; PL= Posteriorly Located

From the data in Table 2 it is clear that the human humerus and radius do not share the nutrient foramen location with any other of the non-human long bones studied. The human humerus is the only bone where the main nutrient foramen has an anterior, distal and medially located position. The foramen in sheep, deer and pig radius is on the posterior and proximal portion of the bone, as in the human radius, although the latter is the only bone where the foramen is medially located.

The nutrient foramen in the human ulna has the same location as in chicken, duck, sheep and pig ulnae. As for human femur and tibia, the foramen location is the same as in pig, deer and sheep radii. However, their differentiation (based on foramen location) would be difficult only in case of very young juvenile individuals that may not have developed a number of features that might help distinguishing a radius from a femur, such as the linea aspera in the femur.

Figures 1-2 show two right humeri, a human one (top) and that of a sheep (below). The location of the foramen can be seen medial in the human and posterior in the non-human. 

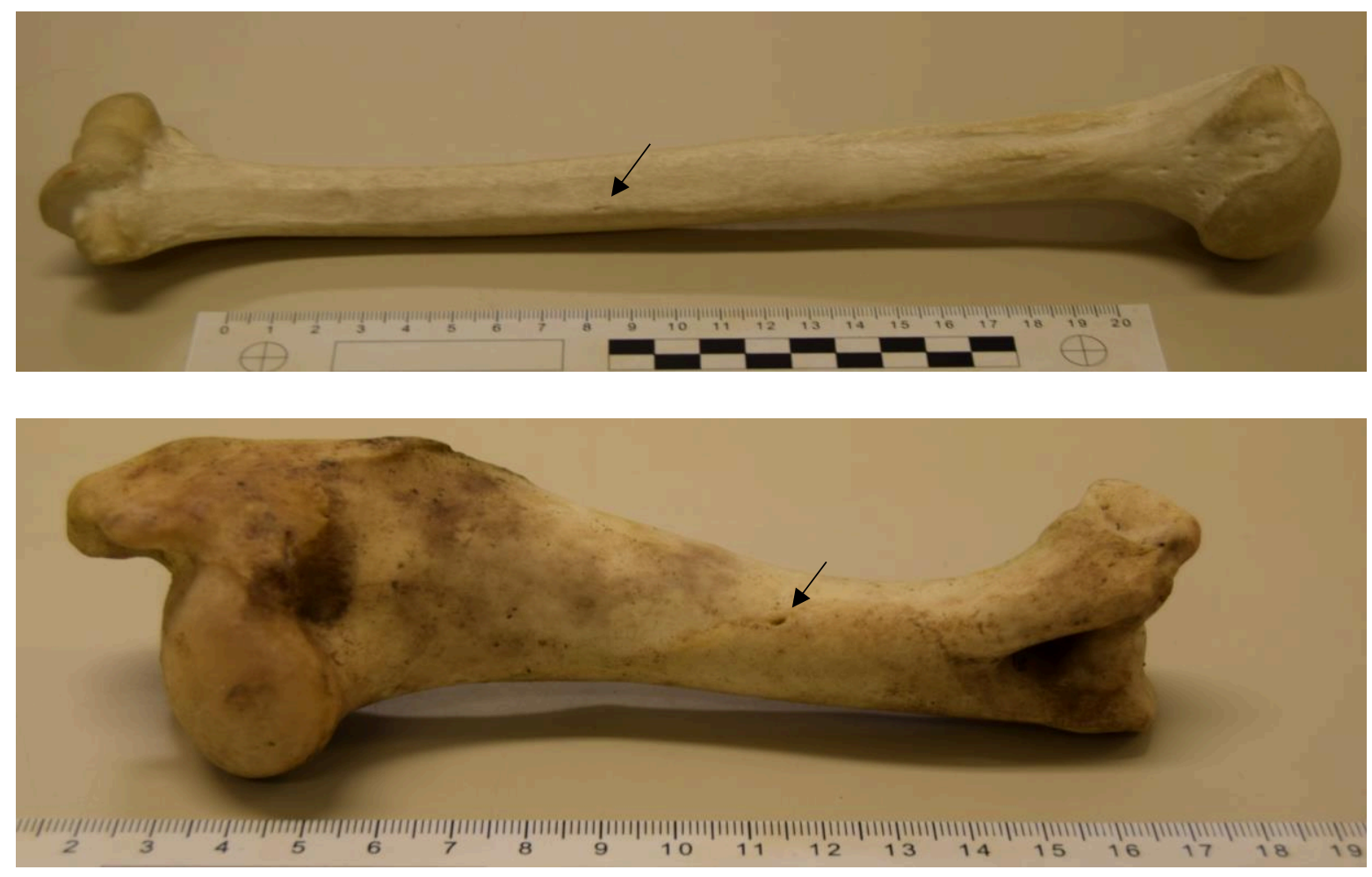

\section{Appearance}

For each foramen, shape, vascular groove details (if any) and orientation are shown in Table 3. The morphology of the foramen itself and its vascular groove was observed macroscopically and the shape of the canal entrance was visualised more clearly in the micro CT-scans. With regard to the vascular grooves, indentations through which the vessels flow across the bone and enter the nutrient foramen, some foramina did not have any visible vascular groove; in these cases, the visible shape was that of the foramen alone.

Table 3. Nutrient foramina appearance

\begin{tabular}{|c|c|c|c|c|c|c|}
\hline & Human & Sheep & Deer & Pig & Chicken & Duck \\
\hline H & $\begin{array}{l}\text { U-shaped } \\
\text { M-L }\end{array}$ & $\begin{array}{l}\text { Drop-shaped } \\
\text { No groove } \\
\text { M-L }\end{array}$ & $\begin{array}{l}\text { Drop-shaped } \\
\text { no groove } \\
\text { M-L }\end{array}$ & $\begin{array}{l}\text { Pointed drop- } \\
\text { shaped, deep } \\
\text { No groove }\end{array}$ & $\begin{array}{l}\text { Drop/Inverse } \\
\text { drop-shaped or } \\
\text { oval }\end{array}$ & $\begin{array}{l}\text { Drop-shaped } \\
\text { or oval }\end{array}$ \\
\hline $\mathbf{R}$ & $\begin{array}{l}\text { Drop/Inverse/ } \\
\text { Pointed drop- } \\
\text { shaped } \\
\text { Small or no } \\
\text { groove }\end{array}$ & $\begin{array}{l}\text { Inverse } \\
\text { rounded V- } \\
\text { shaped } \\
\text { Long } \\
\text { narrowing }\end{array}$ & $\begin{array}{l}\text { Drop/Inverse } \\
\text { drop-shaped or } \\
\text { dot } \\
\text { Small or no } \\
\text { groove }\end{array}$ & $\begin{array}{l}\text { Inverse V- } \\
\text { shaped } \\
\text { Long shallow } \\
\text { groove }\end{array}$ & $\begin{array}{l}\text { Linear or } \\
\text { drop-shaped or } \\
\text { rounded }\end{array}$ & $\begin{array}{l}\text { Linear } \\
\text { Long narrow } \\
\text { groove }\end{array}$ \\
\hline
\end{tabular}




\begin{tabular}{|c|c|c|c|c|c|c|}
\hline & & $\begin{array}{l}\text { groove or no } \\
\text { groove }\end{array}$ & & & & \\
\hline $\mathbf{U}$ & $\begin{array}{l}\text { Rounded } \\
\text { V-shaped } \\
\text { Long narrow } \\
\text { groove }\end{array}$ & $\begin{array}{l}\text { Inverse drop- } \\
\text { shaped }\end{array}$ & Dot & $\begin{array}{l}\text { Drop-shaped } \\
\text { Very small } \\
\text { round groove }\end{array}$ & Drop-shaped & $\begin{array}{l}\text { Narrow } \\
\text { drop-shaped } \\
\text { Long groove }\end{array}$ \\
\hline $\mathbf{F}$ & $\begin{array}{l}\text { Drop/Pointed } \\
\text { drop/Inverse } \\
\text { drop-shaped }\end{array}$ & $\begin{array}{l}\text { Pointed drop- } \\
\text { shaped } \\
\text { Small or no } \\
\text { groove }\end{array}$ & $\begin{array}{l}\text { Drop/ } \\
\text { Pointed } \\
\text { drop-shaped } \\
\text { Small narrow } \\
\text { groove } \\
\text { L-M }\end{array}$ & $\begin{array}{l}\text { Pointed drop/ } \\
\text { Drop-shaped } \\
\text { or Inverse V } \\
\text { with long deep } \\
\text { groove }\end{array}$ & $\begin{array}{l}\text { Inverse drop/ } \\
\text { Drop-shaped } \\
\text { or oval }\end{array}$ & Drop-shaped \\
\hline $\mathbf{T}$ & $\begin{array}{l}\text { Rounded V- } \\
\text { shaped } \\
\text { Long widening } \\
\text { very deep } \\
\text { groove }\end{array}$ & $\begin{array}{l}\text { Rounded V- } \\
\text { shaped } \\
\text { Long straight } \\
\text { /widening } \\
\text { /narrowing } \\
\text { groove } \\
\text { P-A }\end{array}$ & $\begin{array}{l}\text { Long pointed } \\
\text { drop-shaped } \\
\text { Deep groove }\end{array}$ & Pointed drop & $\begin{array}{l}\text { Pointed drop- } \\
\text { shaped } \\
\text { Wide deep } \\
\text { long groove }\end{array}$ & $\begin{array}{l}\text { V-shaped } \\
\text { Widening } \\
\text { long groove }\end{array}$ \\
\hline
\end{tabular}

$\mathrm{H}=$ humerus; $\mathrm{R}=$ radius; $\mathrm{U}=\mathrm{ulna} ; \mathrm{F}=$ femur; $\mathrm{T}=$ tibia; $\mathrm{M}-\mathrm{L}=$ medial-lateral; $\mathrm{L}-\mathrm{M}=$ lateral-medial; $\mathrm{P}-\mathrm{A}=$ posterioranterior

As seen in the table 3, in some human and non-human long bones the appearance of the primary nutrient foramen can vary. For reference, the main shapes occurring in the human bones are shown in the images below (Fig 3 a-e):
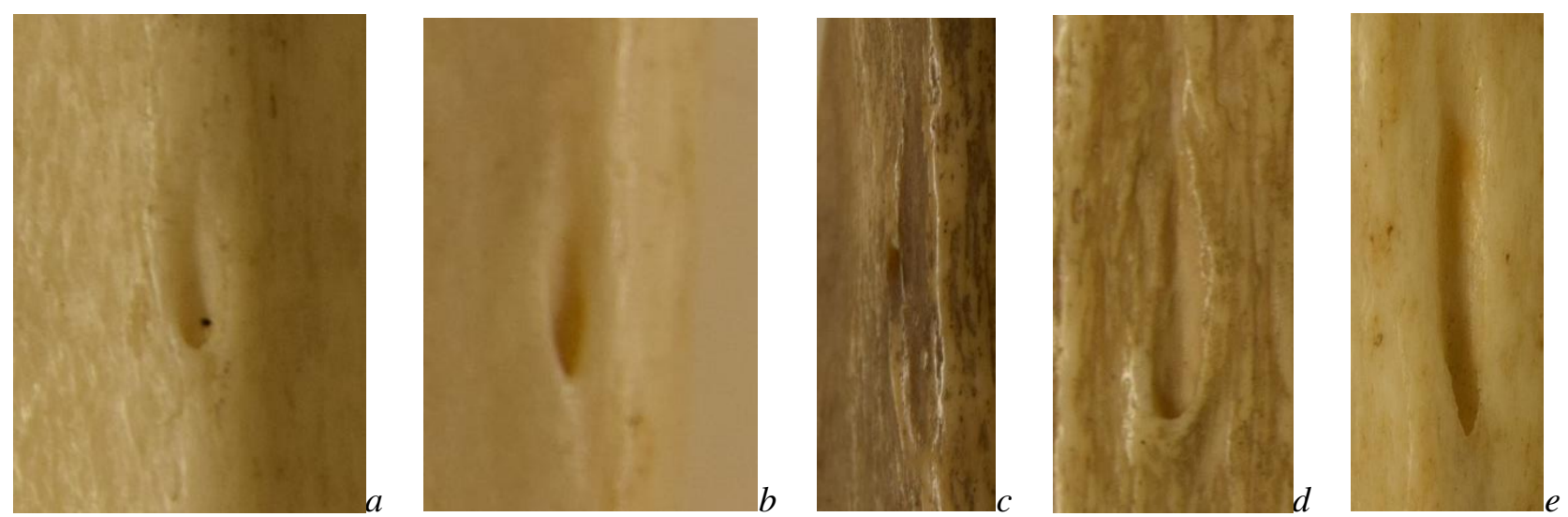

Fig. 3 a-e. Human nutrient foramina (not in scale). From left to right: a) U-shaped (humerus), b) pointed drop-shaped (radius), c) rounded V-shaped with long groove (ulna), d) drop-shaped (femur), e) rounded Vshaped with long widening deep groove (tibia) 
Figure 4 shows the variations observed expressed in percentages.

\section{CHICKEN HUMERUS CHICKEN RADIUS CHICKEN FEMUR DEER RADIUS DEER FEMUR}
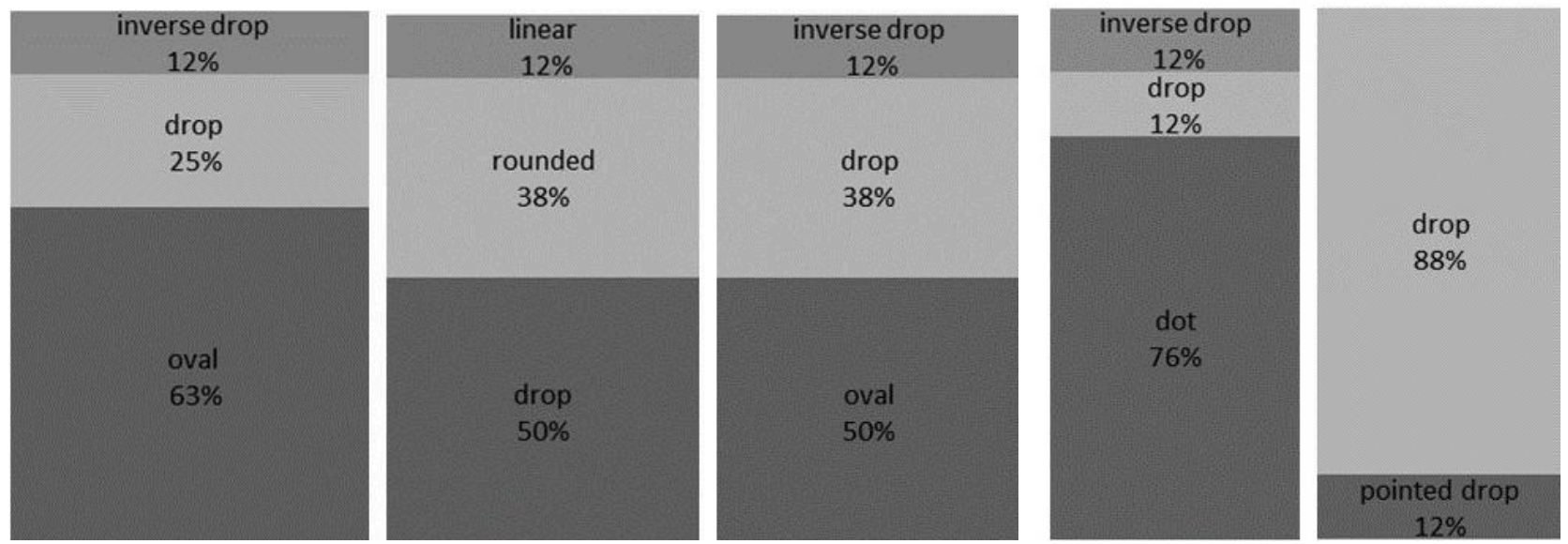

PIG FEMUR

SHEEP TIBIA

HUMAN RADIUS

HUMAN FEMUR
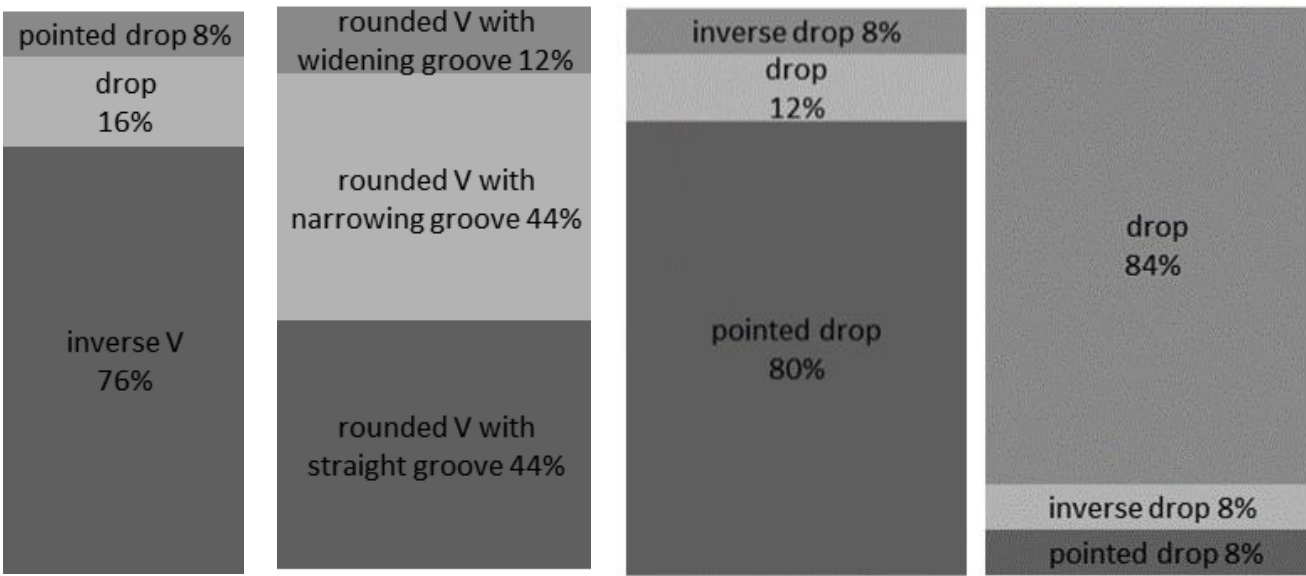

Fig. 4. Variations of nutrient foramen appearance in human and non-human long bones (following Corrieri, 2018).

Most of the bones present in Figure 4 showed a predominant appearance of nutrient foramen and relatively little variation; chicken foramina and the groove of sheep tibiae showed more substantial variations.

One example of a non-human foramen is shown in Figure 5. 


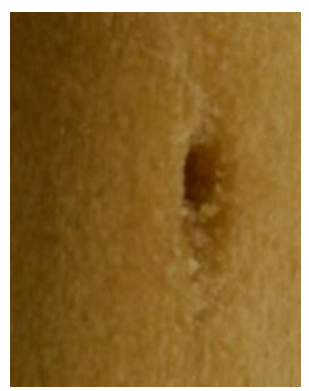

Fig. 5. Non-human nutrient foramen (classified as oval in shape) from a duck humerus (not to scale)

In some long bones of different species the nutrient foramina have the same appearance, as shown in Table 4.

Table 4. Nutrient foramina appearances that occur in multiple bones and species

\begin{tabular}{|l|l|l|}
\hline \multicolumn{1}{|c|}{ Appearance } & \multicolumn{1}{c|}{ Species } & \multicolumn{1}{c|}{ Bone } \\
\hline \multirow{4}{*}{ Drop-shaped } & Human & Femur \\
\cline { 2 - 3 } & Pig & Femur \\
\cline { 2 - 3 } & Chicken & Humerus; radius; ulna; femur \\
\cline { 2 - 3 } & Duck & Humerus; femur \\
\hline \multirow{2}{*}{$\begin{array}{l}\text { Drop/pointed drop-shaped with } \\
\text { small or no groove }\end{array}$} & Human & Femur \\
\cline { 2 - 3 } & Sheep & Radius \\
\cline { 2 - 3 } $\begin{array}{l}\text { Rounded V-shaped with long } \\
\text { widening groove }\end{array}$ & Deer & Tibia \\
\cline { 2 - 4 } & Human & Tibia \\
\hline
\end{tabular}

The nutrient foramen appearance in the human humerus is unique (when compared to the species considered in this study), therefore its identification should be possible.

The human radius might share the foramen appearance with deer radii and sheep femora. In this study most of the deer radii observed $(76 \%)$ had the foramen shape characterised as a small dot; if this is the case, the deer radius might create confusion where the foramen is drop or inverse dropshaped. The foramen on a sheep femur can be difficult to distinguish from that in a human radius, as the area where it is located is flat on both bones; in this case, using other variables might help with the origin identification. As for the human ulna, no other ulnae or limb bones have the same appearance. 
The nutrient foramen of the human femur has a common shape shared with many other non-human bones: chicken humerus, radius, ulna and femur; duck humerus and femur; pig femur and tibia; and sheep ulna. The location of the foramen in the human femur (on lateral or medial to the linea aspera), might help in the identification process.

In the human tibia, the characteristics of the nutrient foramen are quite distinct from other tibiae. However, the foramen might appear similar to that of a sheep tibia. In this case, the vascular groove appearance can be the key for the differentiation; in human tibiae, the vascular groove is always widening, while in sheep tibiae it can show variations and a specific orientation.

\section{Direction}

Table 5 shows the direction in which the nutrient canal enters the long bones of each of the species considered, as detected with a hypodermic needle.

Table 5. Nutrient foramina direction. The directions are either P-D (Proximal to Distal) or D-P (Distal to Proximal).

\begin{tabular}{|c|c|c|c|c|c|c|}
\hline & Human & Sheep & Deer & Pig & Chicken & Duck \\
\hline Humerus & P-D & P-D & P-D & P-D & P-D & P-D \\
\hline Radius & D-P & D-P & D-P & D-P & P-D & P-D \\
\hline Ulna & D-P & D-P & D-P & D-P & P-D & P-D \\
\hline Femur & D-P & P-D & P-D & D-P & D-P & P-D \\
\hline Tibia & P-D & P-D & P-D & P-D & P-D & P-D \\
\hline
\end{tabular}

In humeri and tibiae of all species considered, the nutrient canal runs from proximal to distal direction. As for radii and ulnae, in human, sheep, deer and pig the canal runs in a distal-proximal direction, while it runs in a proximal-distal direction in chicken and duck. Human femora share the distal-proximal canal direction with pig and chicken.

\section{Shape from micro-CT scans}

The different shapes of the nutrient foramina, divided by species and long bones, are shown in Figures 6 and 7. Two points of view were considered: exterior-interior (XY plane) and proximaldistal/distal-proximal (YZ plane). 
Figure 6. Foramina shapes, XY plane (not to scale). Since the deer left radius foramen was too small and undetectable in the scans, two right radii were scanned. Pig right radius and right ulna were not available for scanning. $\mathrm{RH}=$ right humerus; $\mathrm{LH}=$ left humerus; $\mathrm{RR}=$ right radius; $\mathrm{LR}=$ left radius; $\mathrm{RU}=$ right ulna; $\mathrm{LU}=$ left ulna; $\mathrm{RF}=$ right femur; $\mathrm{LF}=$ left femur; $\mathrm{RT}=$ right tibia/tibiotarsus; $\mathrm{LT}=$ left tibia/tibiotarsus

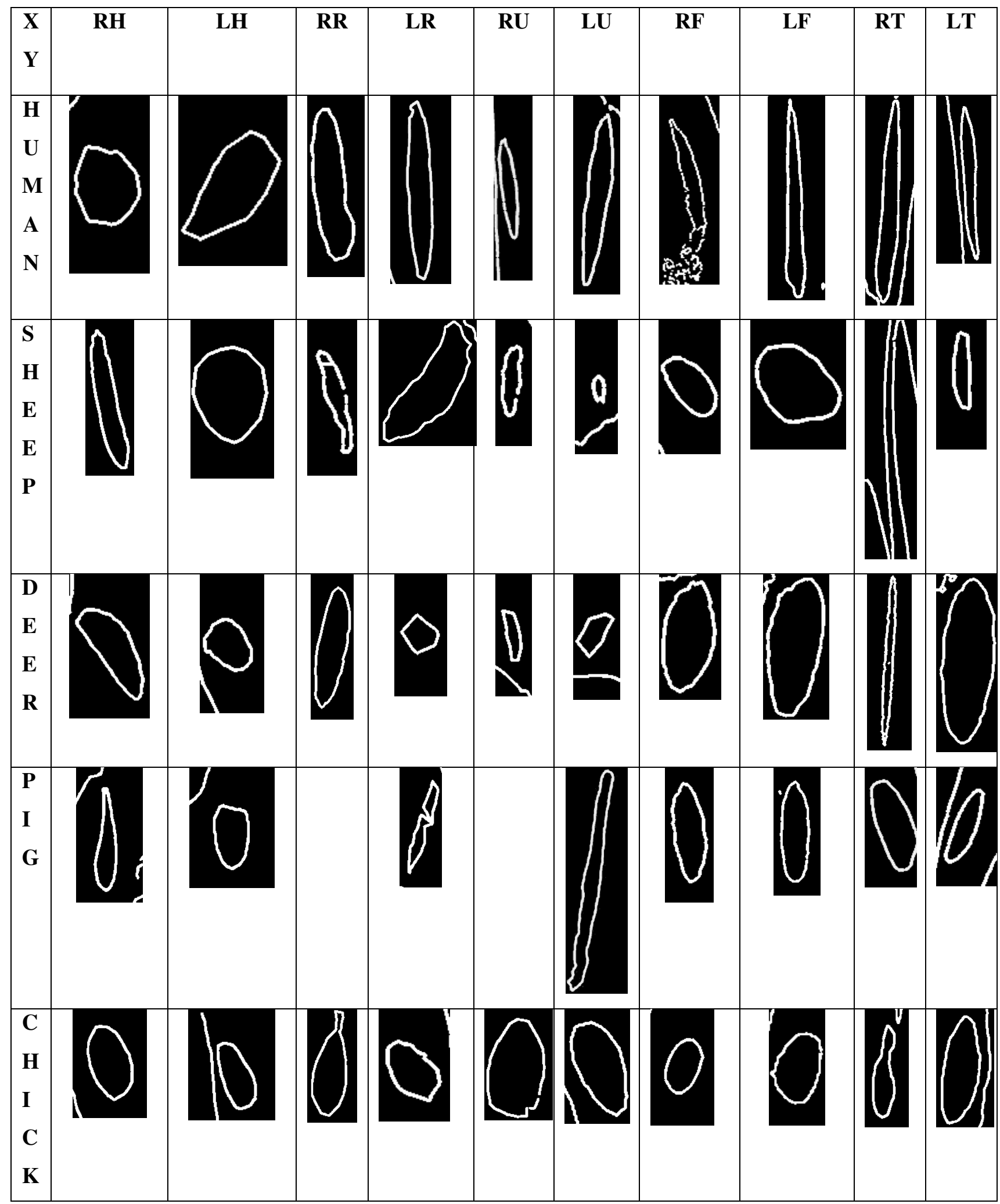




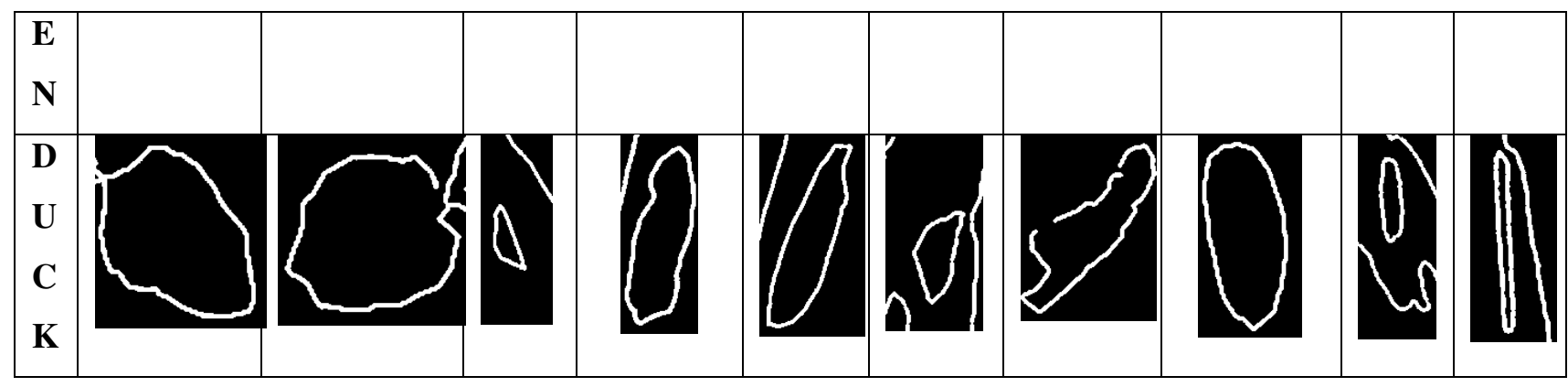

In the human humerus the foramen appears drop-shaped; only one of the sheep humeri seems to share the same shape, although here the drop is more rounded. As for the human radius, the shape of the foramen is a long oval, shared with pig femur and tibia, and only in one case both for deer radius and sheep humerus.

The pointed oval shape in human ulna and the long, pointed, narrow drop shape in the human femur and tibia are not found on any other non-human bone considered in this study.

The human humerus is the only bone where the foramen shape as seen from the YZ plane corresponds to the one seen from the XY plane (Figure 7). In the radius, ulna, femur and tibia the shape of the foramen as seen from its entrance (proximal or distal) does not correspond to the shape seen from the exterior-interior point of view. The shapes on the YZ plane vary even within the same species; as one can see from the images, in many cases right and left foramen shape of each bone are different.

Figure 7. Foramina shapes, YZ plane

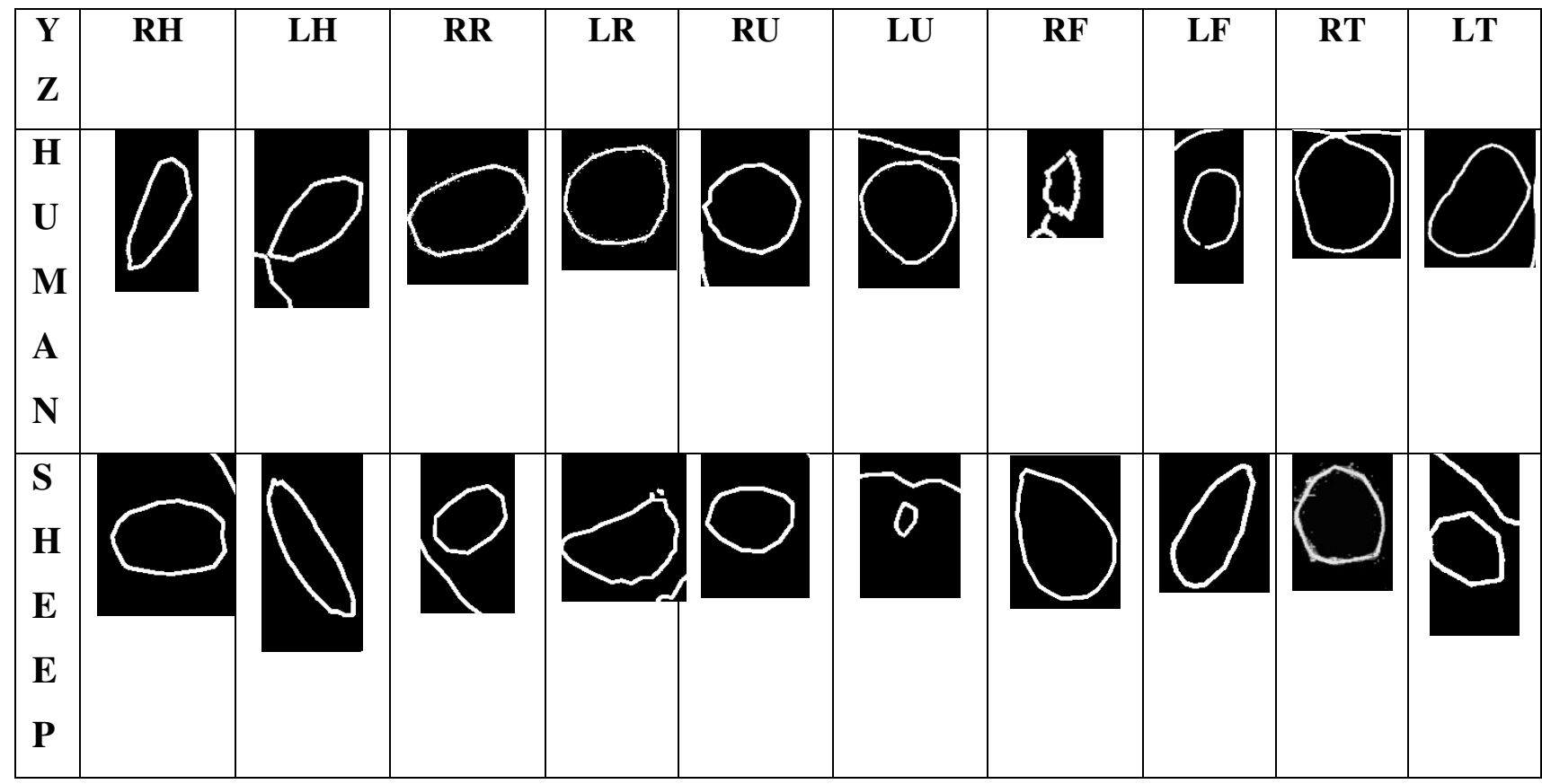




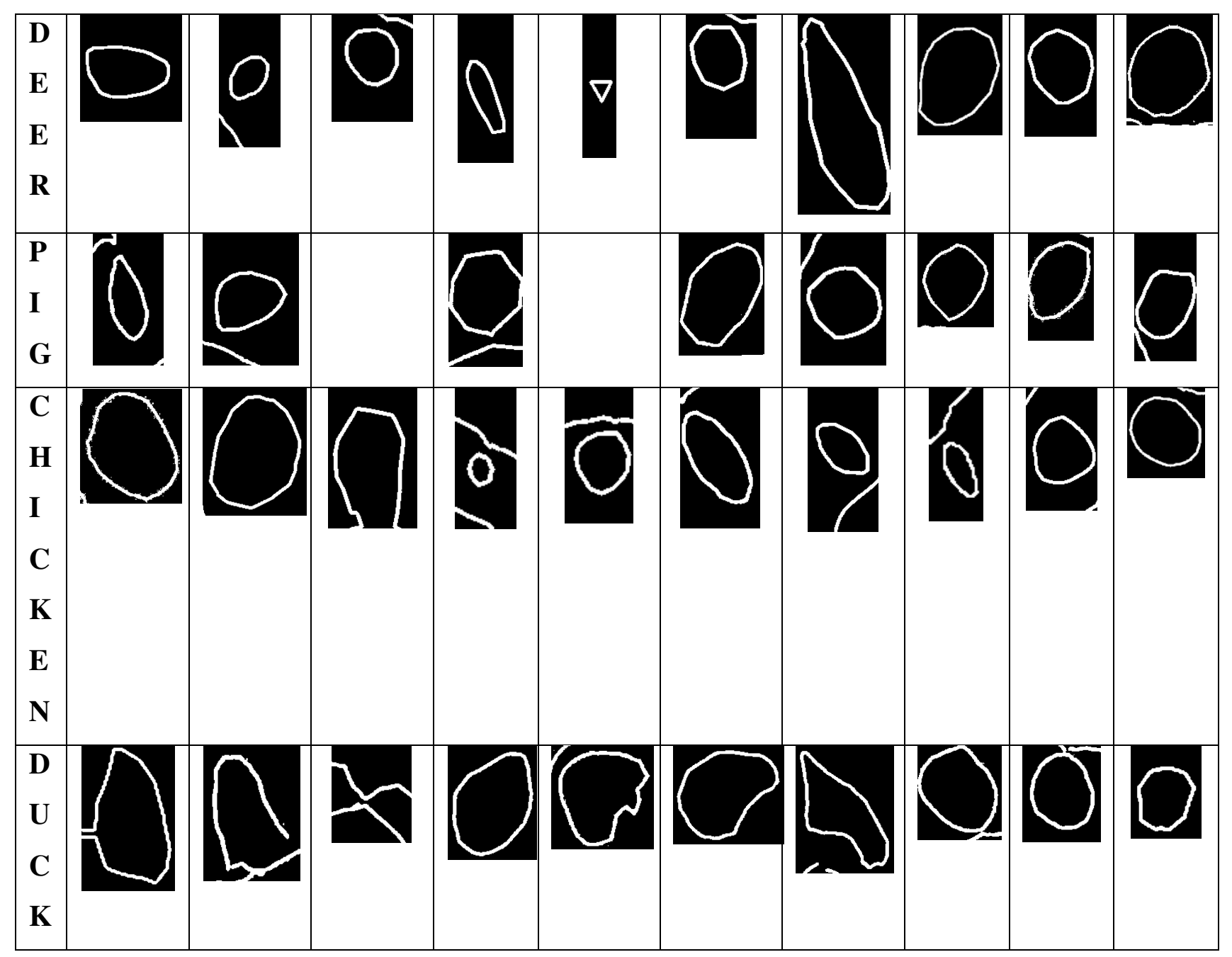

Angle of the nutrient canal from micro-CT scans

Figure 8 shows the measurement of the nutrient canal angle, on the XZ plane (side view). The blue lines represent the selected region of interest of the bone, after the surface determination and surface extraction processes. The nutrient canal was clearly visible in the 3D reconstruction of the selected regions, after surface determination and extraction were applied (Fig. 9). 

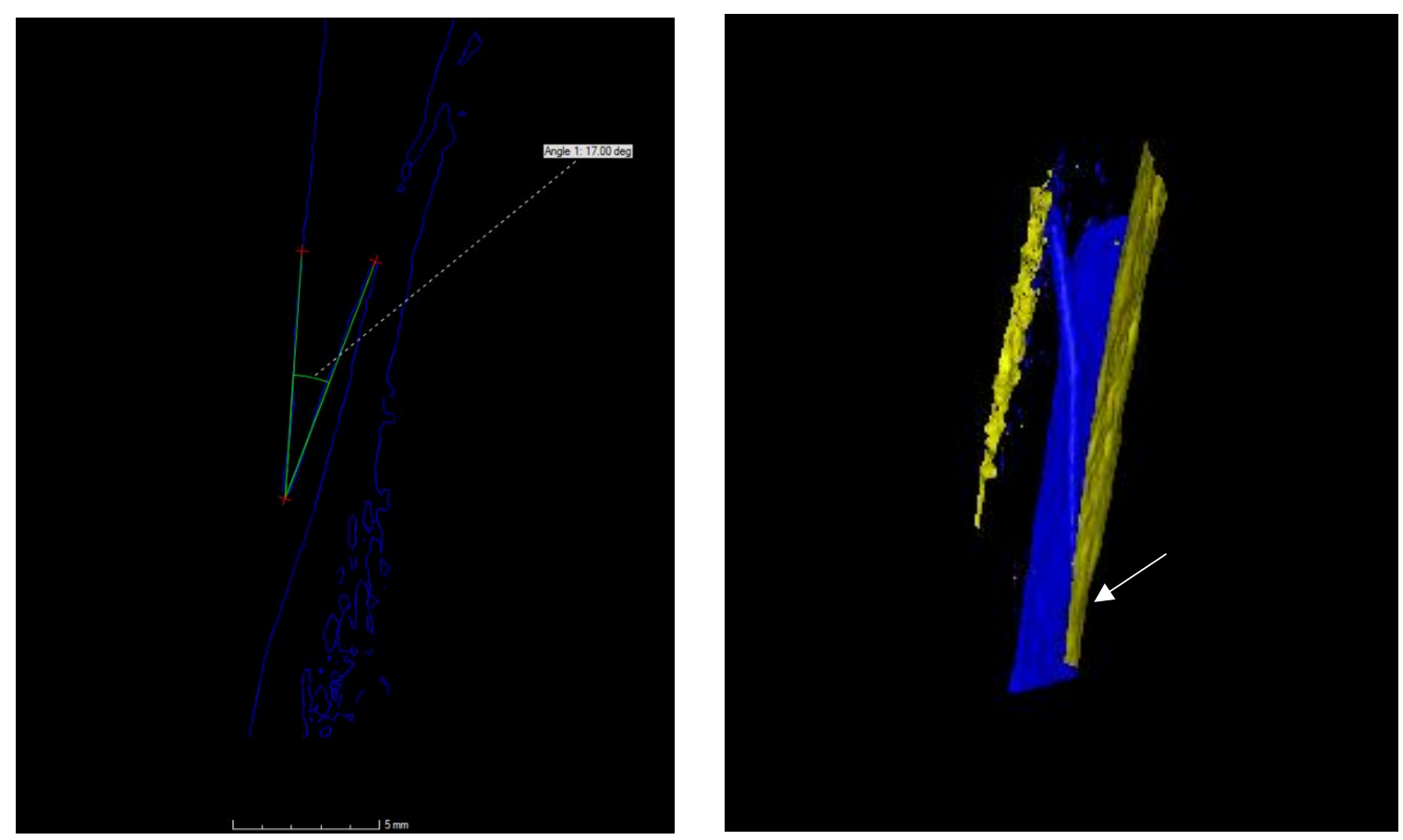

Fig. 8 (left): Nutrient canal angle of a deer tibia, XZ view; Fig. 9. (right): 3D reconstruction of the main nutrient canal of a human left femur (canal entrance and cortical bone are indicated by the arrow)

Table 6 shows the minimum and maximum values obtained for each bone.

Table 6. Nutrient foramina angle degrees (minimum and maximum). As for pig radius and ulna, only one sample per bone was scanned, therefore only one value is available

\begin{tabular}{|c|c|c|c|c|c|c|c|c|c|c|c|c|}
\hline & \multicolumn{2}{|c}{ Human } & \multicolumn{2}{c|}{ Sheep } & \multicolumn{2}{c|}{ Deer } & \multicolumn{2}{c|}{ Pig } & \multicolumn{2}{c|}{ Chicken } & \multicolumn{2}{c|}{ Duck } \\
\hline & Min. & Max. & Min. & Max. & Min. & Max. & Min. & Max. & Min. & Max. & Min. & Max. \\
\hline Humeri & $1^{\circ} 73^{\prime}$ & $1^{\circ} 74^{\prime}$ & $1^{\circ} 37^{\prime}$ & $1^{\circ} 85^{\prime}$ & $1^{\circ} 15^{\prime}$ & $1^{\circ} 51^{\prime}$ & $1^{\circ} 54^{\prime}$ & $1^{\circ} 73^{\prime}$ & $1^{\circ} 23^{\prime}$ & $1^{\circ} 33^{\prime}$ & $1^{\circ} 46^{\prime}$ & $1^{\circ} 66^{\prime}$ \\
\hline Radii & $1^{\circ} 32^{\prime}$ & $1^{\circ} 42^{\prime}$ & $1^{\circ} 28^{\prime}$ & $1^{\circ} 42^{\prime}$ & $1^{\circ} 22^{\prime}$ & $1^{\circ} 94^{\prime}$ & $1^{\circ} 31^{\prime}$ & $1^{\circ} 37^{\prime}$ & $1^{\circ} 51^{\prime}$ & $1^{\circ} 18^{\prime}$ & $1^{\circ} 31^{\prime}$ \\
\hline Ulnae & $1^{\circ} 14^{\prime}$ & $1^{\circ} 46^{\prime}$ & $1^{\circ} 14^{\prime}$ & $1^{\circ} 37^{\prime}$ & $1^{\circ} 14^{\prime}$ & $1^{\circ} 35^{\prime}$ & $1^{\circ} 20^{\prime}$ & $1^{\circ} 30^{\prime}$ & $1^{\circ} 78^{\prime}$ & $1^{\circ} 57^{\prime}$ & $1^{\circ} 13^{\prime}$ \\
\hline Femora & $1^{\circ} 14^{\prime}$ & $1^{\circ} 80^{\prime}$ & $1^{\circ} 33^{\prime}$ & $1^{\circ} 77^{\prime}$ & $1^{\circ} 32^{\prime}$ & $1^{\circ} 48^{\prime}$ & $1^{\circ} 17^{\prime}$ & $1^{\circ} 19^{\prime}$ & $1^{\circ} 48^{\prime}$ & $1^{\circ} 55^{\prime}$ & $1^{\circ} 42^{\prime}$ & $1^{\circ} 50^{\prime}$ \\
\hline Tibiae & $1^{\circ} 60^{\prime}$ & $1^{\circ} 80^{\prime}$ & $1^{\circ} 13^{\prime}$ & $1^{\circ} 15^{\prime}$ & $1^{\circ} 17^{\prime}$ & $1^{\circ} 25^{\prime}$ & $1^{\circ} 50^{\prime}$ & $1^{\circ} 58^{\prime}$ & $1^{\circ} 14^{\prime}$ & $1^{\circ} 15^{\prime}$ & $1^{\circ} 70^{\prime}$ & $1^{\circ} 12^{\prime}$ \\
\hline
\end{tabular}

The only two human bones whose nutrient canals seem to enter at a very specific angle are the humerus and the tibia. In both human humeri the nutrient canal enters the bone at the same angle. However, the angle seen in the human humerus, albeit very specific, cannot exclusively be linked to a human bone, as in the sheep humerus and femur, deer radius, pig humerus, chicken and duck ulna 
the ranges of angles include $1^{\circ} 73^{\prime} / 74^{\prime}$. This means that in these non-human bones the nutrient canal may enter at the same angle as observed in the human humerus.

In the human radius, the range of the angle degrees is slightly larger. In sheep humerus, radius, ulna and femur; deer humerus, radius, ulna, and femur (which shows a range very similar to the one seen in human radius); chicken humerus, radius and ulna and duck femur, the angle values range from $1^{\circ} 32^{\prime}$ to $1^{\circ} 42^{\prime}$; therefore, they can have the nutrient canal at the same angle as in the human radius. In the human ulna and femur, the range of angles becomes even larger, especially for the femur. In this case, the canal angle calculation might not be a useful tool for the identification of the human or non-human origin of a fragmented bone.

Among the human bones, the tibia seems to have a unique angle range; only in duck tibia the canal is seen to enter at a similar angle, although in this case the measurement range is larger than the one seen in the human tibia.

\section{DISCUSSION}

In the study presented in this paper 364 long bones were employed to analyse any human vs nonhuman differences in the location, appearance, direction, shape and angle of the nutrient foramina of human and non-human long bones (humeri, radii, ulnae, femora and tibiae).

\section{Location}

None of the foramina locations can be associated to a specific species. The only exception is the human humerus, as it is the only human bone that has a unique foramen location. The unique location of the humeral nutrient foramen, between the coracobrachialis and brachialis muscles, is well known in clinical medicine, as the humerus is supplied by a single nutrient artery that is usually affected in case of fractures (Menck et al., 1997; Xue et al., 2016). Thus this location enables the scientist presented with a fragment big enough to be identified as a humerus from a particular side (left or right), to identify it as human if the location of the foramen is anterior, distal and medially located.

In all long bones, the primary nutrient foramina are located near major muscle attachments, as they are essential for a continuous blood supply (Kizilkanat et al., 2007). More precisely, foramina lay on the flexor surface of the bones (Buckwalter et al., 2001).The human radius, like the humerus, 
does not share the foramen location with any other non-human bone considered in this study. However, unless the fragment is big enough to see the actual shape of the bone, its side or any other feature such as muscular attachments, location alone might not be useful for origin identification. Nevertheless, location can be useful if other characteristics such as appearance are considered.

\section{Appearance}

With regard to appearance, the human species seems to have the most varied pattern. None of the non-human species follows a specific pattern in foramina appearance. Only chicken and deer have the drop-shape recurring in all bones, but this is not always the case, at least as observed in the current study.

Although variations in foramina appearance were seen on human radius and femur, and some similarities between human and non-human foramina (e.g. human radius and sheep femur) were noticed, the appearance resulted to be the most effective for the differentiation of human/nonhuman bone.

There are some shapes that do not appear on human bones: V-shape, which has been seen only in pig and duck; oval and linear, seen only in birds. If a nutrient foramen shows one of these shapes, the bone is likely to be non-human. Table 3 may be used as a reference in cases of a nutrient foramina-based bone origin identification.

In the case of very fragmented bones, the specific orientation might not be noticeable, but it is useful to know it, because the foramina that have a specific orientation would appear oblique in any case, when compared to the direction of the bone growth lines (Iannotti, 1990). The orientation alone might even help understanding the origin, since among human bones only the humerus has a foramen with a medial to lateral orientation.

\section{Direction}

When direction is considered, the nutrient canal in human limb bones opens towards the elbow in the upper limb and away from the knee in the lower limb (Longia et al., 1980; Williams et al., 1995). The direction pattern of the nutrient foramina in non-human species does not always follow the rule seen in humans (Rao and Kothapalli, 2014). The present study shows that the porcine bones share the same nutrient canal direction pattern with the human bones. As there are only two possible directions, there is limited variability between species. Identifying the origin of fragmented bones only by direction of foramina is not possible, but in any case knowing the direction of every human 
long bone might help in the process, when other features such as appearance and location are taken into consideration.

\section{Shape from micro-CT scans}

The results from the micro-CT scans revealed that the nutrient foramina in the XY plane, were unique in human bones in that they were the only ones that showed specific and consistent shapes that appeared very similar to each other, with the right bone equal to the left one. The foramina shape of the non-human species showed less consistency and more variation. The shape as seen in the XY plane was a very helpful parameter to identify the origin, as in most cases the human bones do not share the foramen shape with any other non-human bone.

Conversely, the shape as seen in the YZ plane was not useful. Indeed, in none of the bones, either human or non-human, the foramina shapes followed a fixed pattern that could be related to a specific species; in human bones there was no correspondence even between left and right sides of the same long bone, except for the humerus.

It should be noted that the results of this part of the study might have some limitations, as only two of each long bones were scanned. With more bones, more (or less) inter- and intra-species variation might be expected.

\section{Angle from micro-CT scans}

Lastly, in human bones, the angle at which the nutrient canal enters as measured from the micro-CT scans can range from $1^{\circ} 60^{\prime}$ to $1^{\circ} 80^{\prime}$, which is a very large range that does not allow a secure origin identification. Furthermore, for most human bones the angle was shared with non-human species, meaning that in a non-human bone the nutrient canal may enter the cortex at the same angle as in a human bone.

This variable alone is not reliable as a parameter; it might be helpful only if used alongside other parameters. For example, if a bone fragment is thought to be a human tibia (on the basis of different parameters), the angle of the nutrient canal can be used to confirm whether it is consistent or not with a human tibia, in order to strengthen the diagnosis.

It is worth noting that inter- and intra-observer variation can be present, particularly in the assessment of the appearance and shape of the foramina, as the perception and description of the shapes might differ if the visual analysis is performed by a different observer or repeated by the same observer on the same sample. The detection of location and direction of the foramina could be 
prone to bias as strictly related to the experience of the observer and his/her knowledge of the nonhuman bone anatomy. As for the angle of the nutrient canal, no intra-observer variation was observed; guidelines on the specific point of measurement can reduce inter-observer variability.

\section{Practical recommendations}

The methods and variables tested in this study proved to be suitable for the purpose of bone origin identification. The location of the foramen can be a very useful parameter, especially if the anatomy of human long bones (and possibly of some common non-human species) is known; when the samples are too fragmented, location becomes less useful alone, but can still be helpful if considered alongside other data. Direction is not suitable to be used as a sole parameter, as it can be only proximal-distal or distal-proximal, but it can be useful as complimentary information that can be cross-checked with others. Among the variables morphologically examined, the appearance of the nutrient foramina was proven to be the most effective one; in any case, it is advisable to use the other parameters for safer results.

As regards the features requiring the use of a micro-CT scanner, the canal entrance shape proved to be very informative, as most of the shapes seen in the human bones were not seen on any other nonhuman bone; however, only the XY plane should be considered. Since the shapes as seen on the micro-CT scans and those visible by the naked eye are not the same (because the latter include the vascular groove), the CT-scanning method does not represent just an additional verification, but a very useful tool for bone identification.

The angle of the canal at the cortical bone was the least informative variable; it cannot be used alone, but just for a data cross-check. If micro-CT scanning is employed anyway, it is recommended to calculate the angle, since its calculation takes seconds; conversely, a CT-scan made with the sole purpose of angle calculation is not recommended.

Further research must be undertaken on the differentiation between human and non-human nutrient foramina, possibly involving different non-human species and a larger sample size to use for microCT scanning, in order to evaluate the presence of intra-species variability.

\section{ACKNOWLEDGEMENTS}

The authors would like acknowledge the significant input and enormous help from Dr Fiona Brock, Cranfield Forensic Institute. The authors would also like to thank Oxford Archaeology and the Grant Museum of Zoology in London that allowed access to their collections of non-human bones. 
This research did not receive any specific grant from funding agencies in the public, commercial, or not-for-profit sectors.

\section{REFERENCES}

Anstett, E., Dreyfus, J.M., 2015. Human Remains and Identification: Mass Violence, Genocide and "the Forensic turn". Manchester University Press, Manchester.

Beisaw, A.M., 2013. Identifying and Interpreting Animal Bones. A Manual. Texas A\&M

University Anthropology Series, no. 18. Everbest Printing \& Co, Hong Kong.

Bostrom, M., Yang, X., Koutras, I., 2000. Biologics in bone healing. Curr. Opin. Orthop. 11, 403412.

Buckwalter, J.A., Stanish, W.D., Rosier, R.N., Schenck, R.C. Jr, Dennis, D.A., Coutts, R.D., 2001. The increasing need for non-operative treatment of patients with osteoarthritis. Clin. Orthop. Relat. Res. 385, 36-45.

Campos, F.F., Pellico, L.G., Alias, M.G., Fernandez-Valencia, R., 1987. A study of nutrient foramina in human long bones. Surg. Radiol. Anat. 9, 251-255.

Corrieri, B., 2018. Human vs Non-human Bone. Identification and Differentiation of Fragmented Skeletal Remains Using Non-Destructive Methods (Ph.D thesis). Cranfield University, Shrivenham. Croker, S.L., Clement, J.G., Donlon, D., 2009. A comparison of cortical bone thickness in the femoral midshaft of humans and two non-human mammals. HOMO - J. Comp. Hum. Biol. 60, 551-565.

Dirkmaat, D. (Ed.), 2014. A Companion to Forensic Anthropology. Wiley-Blackwell, Chichester.

Dongchoon, A., 2013. Anatomical study on the diaphyseal nutrient foramen of the femur and tibia of the German shepherd dog. J. Vet. Med. Sci. 75, 803-808.

Dumont, E.R., 2010. Bone density and the lightweight skeletons of birds. Proc. R. Soc. B Biol. Sci. 277, 2193-2198.

Evans, E., 2016. Avian anatomy. In: Lovette, I.J., Fitzpatrick, J.W. (Eds.), The Cornell Lab of Ornithology Handbook of Bird Biology, 3rd ed. Wiley, Chichester, pp. 169-214. 
France, D.L., 2009. Human and Nonhuman Bone Identification: A Color Atlas. CRC Press, Boca Raton, FL.

Franklin, D., Swift, L., Flavel, A., 2016.Virtual anthropology' and radiographic imaging in the Forensic Medical Sciences. Egypt. J. Forensic Sci. 6, 31-43.

Gainor, B.J., Metzler, M., 1986. Humeral shaft fracture with brachial artery injury. Clin. Orthop. Relat. Res. 204, 154-161.

Gantt, D.G., Grine, F.E., Martin, L.B., 2007. HRXCT analysis of hominoid molars: A quantitative volumetric analysis and 3D reconstruction of coronal enamel and dentin. In: Bailey, S.E., Hublin, J.J. (Eds.), Dental Perspectives on Human Evolution. State-of-the Art Research in Dental Palaeoanthropology. Springer, Dordrecht, pp. 117-138.

Hughes, H., 1952. The factors determining the direction of the canal for the nutrient artery in the long bones of mammals and birds. Acta Anat. (Basel) 15, 261-80.

Iannotti, J.P., 1990. Growth plate physiology and pathology. Orthop. Clin. North Am. 21, 1-17. Johnson, V.O., Beckett, S., Márquez-Grant, N., 2017. Differentiating human versus non-human bone by exploring the nutrient foramen: implications for forensic anthropology. Int. J. Legal Med. $131,1757-1763$.

Kizilkanat, E., Boyan, N., Ozsahin, E.T., 2007. Location, number and clinical significance of nutrient foramina in human long bones. Ann. Anat. 189, 87-95.

Klein-Nulend, J., Bacabac, R.G., 2012. Bone Adaptation and Regeneration - New Developments. Int. J. Mod. Phys.: Conf. Ser. 17, 34-43.

Longia, G.S., Ajmani, M.L., Saxena, S.K., Thomas, R.J., 1980. Study of diaphyseal nutrient foramina in human long bones. Act. Anat. (Basel) 107, 399-406.

Marenzana, M., Arnett, T.R., 2013. The key role of the blood supply to bone. Bone Res. 1, 203-215. Menck, J., Dobler, A., Dohler, J.R., 1997. Vascularization of the humerus. Langenbecks Arch. Surg. 382, 123-127.

Rao, S., Kothapalli, J., 2014. The diaphyseal nutrient foramina architecture - a study on the human upper and lower limb long bones. J. Pharm. Biol. Sci. 9, 36-41. 
Rerolle, C., Saint-Martin, P., Dedouit, F., Rousseau, H., Telmon, N., 2013. Is the corticomedullary index valid to distinguish human from nonhuman bones: a multislice computed tomography study. Forensic Sci. Int. 231, 406.e 1-5.

Seymour, R.S., Smith, S.L., White, C.R., Henderson, D.M., Schwarz-Wings, D., 2012. Blood flow to long bones indicates activity metabolism in mammals, reptiles and dinosaurs. Proc. Royal Soc. B: Biol. Sci. 279, 451-456.

Sim, J.H., Dongchoon, A., 2014. Anatomy of the diaphyseal nutrient foramen in the long bones of the pectoral limb of German Shepherds., Korean J. Vet. Res. 54, 179-184.

Sisniega, A., Vaquero, J.J., Desco, M., 2014. Design and Assessment Principles of Semiconductor Flat-Panel Detector-Based X-Ray Micro-CT Systems for Small Animal Imaging. In: Farncombe, T., Iniewski, K. (Eds), Medical Imaging: Technology and Applications. CRC Press, Boca Raton, FL, pp. 109-146.

Stock, S.R., 2011. Micro-Computed Tomography. Methodology and Applications. CRC Press, Boca Raton, FL.

Ward, M.R., Pasterkamp, G., Yeung, A. C., Borst, C., 2000. Arterial remodeling. Mechanisms and clinical implications. Circulation 102, 1186-1191.

Warden, S.J, Mantila, R.S.M., Kersh, M.E., Hurd, A.L., Fleisig, G.S., Pandy, M.G., Fuchs, R.K., 2014. Physical activity when young provides lifelong benefits to cortical bone size and strength in men. Proc. Natl. Acad. Sci. 111, 5337-5342.

Williams, P.L., Bannister, L.H., Berry, M.M., Collins, P., Dyson, M., Dussek, J.E., Ferguson, M.W.J., 1995. Pelvic girdle and lower limb. In: Gray, H. (Ed.), Gray’s Anatomy: The Anatomical Basis for Medicine and Surgery, 38th edition. Churchill Livingstone, Philadelphia, PA, pp. 14341567.

Witkowska, A., Alibhai, A., Hughes, C., Price, J., Klisch, K., Sturrock, C.J., Rultand, C.S., 2014. Computed tomography analysis of guinea pig bone: architecture, bone thickness and dimensions throughout development. PeerJ: e615.

Wu, X., Schepartz, L.A., 2009. Application of computed tomography in paleoanthropological research. Prog. Nat. Sci. 19, 913-921.

Xue, Z., Ding, H., Hu, C., Xu, H., An, Z., 2016. An anatomical study of the nutrient foramina of the human humeral diaphysis. Med. Sci. Monit. 22, 1637-1645. 